\title{
A OBRIGATORIEDADE DO PROCEDIMENTO DE SOLUÇÃO AMISTOSA NO TRÂMITE DE PETIÇÕES NA COMISSÃO INTERAMERIÇANA DE DIREITOS HUMANOS
}

\author{
José Ricardo da Silva Baron ${ }^{1}$ \\ Vladimir Brega Filho ${ }^{2}$
}

\section{RESUMO}

A partir da análise do procedimento de solução amistosa da Comissão Interamericana de Direitos Humanos buscou-se estudar a obrigatoriedade do oferecimento do procedimento para as partes em litígio no Sistema Interamericano de Direitos Humanos. Dessa forma, a partir de levantamento bibliográfico, revisão de normas, decisões e casos da Comissão e Corte Interamericana de Direitos Humanos, concluiu-se, a partir do Caso Caballero Delgado y Santana vs. Colômbia em 1994 e do Plano Estratégico 2017-2021 da Comissão Interamericana, que o oferecimento do procedimento de solução amistosa é uma obrigação da Comissão Interamericana de Direitos Humanos.

Palavras-Chave: Solução Amistosa; Comissão Interamericana de Direitos Humanos; Sistema Interamericano de Direitos Humanos; Obrigatoriedade; Corte Interamericana de Direitos Humanos

\section{THE OBLIGATION OF THE FRIENDLY SETTLEMENT PROCEDURE IN THE PROCESS OF PETITIONS IN THE INTER-AMERICAN COMMISSION ON HUMAN RIGHTS}

\begin{abstract}
Based on the analysis of the friendly settlement procedure of the Inter-American Commission on Human Rights, an attempt was made to study the obligation to offer the procedure for the parties in dispute in the Inter-American Human Rights System. Thus, from the bibliographical survey, review of norms, decisions and cases of the Inter-American Commission and Court of Human Rights, it was concluded, from the Case Caballero Delgado y Santana v. Colombia in 1994 and the 2017-2021 Strategic Plan of the Inter-American Commission, that offering a friendly settlement procedure is an obligation of the Inter-American Commission on Human Rights.

Key-words: Friendly Settlement; Inter-American Commission on Human Rights; InterAmerican Human Rights System; Obligatoriness; Inter-American Court on Human Rights

\section{INTRODUÇÃO}

\footnotetext{
${ }^{1}$ Mestrando em Ciência Jurídica pela Universidade Estadual do Norte do Paraná (UENP), Especialista em Direito do Estado pela Universidade Estadual de Londrina (UEL), Graduado em Direito pela Universidade Estadual de Londrina (UEL), Advogado. Endereço Postal: R. Brasil, no 1014, sala 602, Londrina-PR, CEP: 86010-200. Endereço Eletrônico: joserbaron@ @otmail.com, Lattes: http://lattes.cnpq.br/1371083513510015.

${ }^{2}$ Doutor em Direito pela Pontifícia Universidade Católica de São Paulo (PUC-SP); Mestre em Direito pela Instituição Toledo de Ensino; Professor Associado da Universidade Estadual do Norte do Paraná (UENP); Promotor de Justiça do Ministério Público do Estado de São Paulo (MP-SP). Endereço Postal: Av. Manoel Ribas, n ${ }^{\circ}$ 215, Jacarezinho-P, CEP: 86400-000. Endereço Eletrônico: vladimir@uenp.edu.br, Lattes: http://lattes.cnpq.br/9000467259519005
} 
O Sistema Interamericano de Direito Humanos é o mecanismo internacional para a promoção e proteção dos Direitos Humanos no âmbito do continente americano e, dentre seu escopo de atuação, está o de garantir a reparação por violações perpetradas por Estados membros da Organização dos Estados Americanos.

Para o desenvolvimento de suas funções, o Sistema Interamericano é composto pela Comissão Interamericana de Direitos Humanos, com a função de promover os direitos humanos no âmbito americano, atuar de forma consultiva, receber petições (denúncias), emitir recomendações e enviar casos de violações de direitos humanos para a Corte Interamericana de Direitos Humanos que, por sua vez, tem a função consultiva e contenciosa para os Estados que tenham aceito sua jurisdição, julgando violações de direitos humanos.

A abertura de um caso no Sistema Interamericano ocorre através do Sistema de Petições da Comissão Interamericana que inicia um trâmite ordinário culminando, se houver reconhecimento de violação dos direitos humanos, em recomendações da Comissão para o Estado e, em caso de não atendimento das recomendações e aceite da jurisdição contenciosa da Corte, no envio do caso para a Corte Interamericana de Direitos Humanos para julgamento.

Entretanto, durante o trâmite na Comissão há o caso de vítima e Estado chegarem a um acordo através do procedimento de solução amistosa, sendo que este procedimento ocorre por meio da conciliação, mediação ou qualquer meio de negociação que permita um acordo entre as partes.

A solução amistosa tem passado por transformações ao longo do tempo sendo a mais recente e marcante a que define o procedimento como um dos focos do Plano Estratégico 2017-2021 da Comissão Interamericana, provocando maior presença da solução amistosa no trâmite das denúncias na Comissão.

Posto isso, este estudo pretende analisar, por meio de levantamento bibliográfico, análise de decisões judiciais da Corte Interamericana, resoluções e doutrina, se o oferecimento do procedimento de solução amistosa se trata de um ato vinculado da Comissão Interamericana de Direitos Humanos ou uma faculdade. 
Para tanto, o primeiro capítulo irá tratar do procedimento de solução amistosa como um instrumento da Comissão Interamericana de Direitos Humanos que possibilita a resolução de conflitos de forma alternativa, por meio do acordo entre vítima e Estado.

Por sua vez, o segundo capítulo tratará da solução amistosa como foco do Plano Estratégico 2017-2021 para resolução de conflitos e redução da morosidade processual presente na Comissão Interamericana de Direitos Humanos, por meio da análise de normas e dados a respeito do número de petições apresentadas.

Por fim, o terceiro capítulo tratará especificamente da obrigatoriedade ou não do oferecimento do procedimento de solução amistosa para vítima e Estado, partindo da análise de decisões da Corte Interamericana e da relevância do procedimento a partir do Plano Estratégico 2017-2021.

\section{O PROCEDIMENTO DE SOLUÇÃO AMISTOSA - PREVISÃO LEGAL E COMPOSIÇÃO}

O procedimento de solução amistosa (PSA) é mecanismo da Comissão Interamericana de Direitos Humanos que possibilita a resolução de demandas entre Estado e vítima em comum acordo, sem que seja necessário o acionamento da jurisdição contenciosa da Corte Interamericana de Direitos Humanos. O procedimento é definido pela Comissão nos seguintes termos:

En el marco del sistema de peticiones y casos individuales ante la Comisión Interamericana de Derechos Humanos (en adelante "Comisión" o "CIDH"), el procedimiento de solución amistosa es un proceso facilitado por la Comisión que tiene como objetivo que el Estado concernido y las presuntas víctimas y/o peticionarios/as logren alcanzar un acuerdo, fuera de la vía contenciosa, que permita la solución de la alegada violación de derechos humanos. (COMISIÓN INTERAMERICANA DE DERECHOS HUMANOS, 2013, p. 5)

O instrumento se trata, dentro do Sistema Interamericano de Direitos Humanos, de forma alternativa de resolução de conflitos, uma vez que foge ao procedimento comum de trâmite de casos perante a Comissão Interamericana de Direitos Humanos e envio do caso para a Corte Interamericana.

Como uma forma pacífica de solução de controvérsias, o procedimento de solução amistosa foi previsto, inicialmente, na Convenção Interamericana de Direitos Humanos 
(1969). Entretanto a previsão no referido documento legal ocorre de forma superficial, prevendo apenas a possibilidade de uma solução amistosa de conflitos no âmbito do Sistema Interamericano de Direitos Humanos, sem normatizar no que consiste ou o procedimento que deve ser adotado. Assim, o artigo 48, item 1, "f” e artigo 49 da Convenção Interamericana preveem o procedimento de solução amistosa (PSA) nos seguintes termos:

1. A Comissão, ao receber uma petição ou comunicação na qual se alegue a violação de qualquer dos direitos consagrados nesta Convenção, procederá da seguinte maneira:

$[\ldots]$

f. por-se-á à disposição das partes interessadas, a fim de chegar a uma solução amistosa do assunto, fundada no respeito aos direitos reconhecidos nesta Convenção

Art. 49. Se houver chegado a uma solução amistosa de acordo com as disposições do inciso 1, "f", do art. 48, a Comissão redigirá um relatório que será encaminhado ao peticionário e aos Estados-partes nesta Convenção e posteriormente transmitido, para sua publicação, ao Secretário-Geral da Organização dos Estados Americanos. O referido relatório conterá uma breve exposição dos fatos e da solução alcançada. Se qualquer das partes no caso solicitar, ser-lhe-á proporcionada a mais ampla informação possível (ORGANIZAÇÃO DOS ESTADOS AMERICANOS, 1969, p. 12-13)

O aprofundamento a respeito do procedimento de solução amistosa ocorre no

Regulamento da Comissão Interamericana de Direitos Humanos que normatiza que antes da Comissão se pronunciar sobre o mérito, fixará prazo para as partes se manifestarem sobre a possibilidade de iniciarem o procedimento de solução amistosa. Além disso, o Regulamento da Comissão trata a respeito do procedimento de solução amistosa da seguinte forma:

Artigo 40. Solução amistosa

1. Em qualquer etapa do exame de uma petição ou caso, a Comissão, por iniciativa própria ou a pedido das partes, pôr-se-á à disposição destas a fim de chegar a uma solução amistosa sobre o assunto, fundamentada no respeito aos direitos humanos estabelecidos na Convenção Americana sobre Direitos Humanos, na Declaração Americana e em outros instrumentos aplicáveis.

2. O início e a continuação do procedimento de solução amistosa basear-seão no consentimento das partes.

3. A Comissão, quando assim considerar necessário, poderá atribuir a um ou mais dos seus membros a tarefa de facilitar a negociação entre as partes.

4. A Comissão poderá dar por concluída sua intervenção no procedimento de solução amistosa se advertir que o assunto não é suscetível de solução por esta via ou se alguma das partes decidir retirar-se do mesmo, não concordar 
com sua aplicação ou não mostrar-se disposta a chegar a uma solução amistosa fundamentada no respeito aos direitos humanos.

5. Se for alcançada uma solução amistosa, a Comissão aprovará um relatório que incluirá uma breve exposição dos fatos e da solução alcançada e será transmitido às partes e publicado. Antes de aprovar esse relatório, a Comissão verificará se a vítima da presumida violação ou, se pertinente, seus beneficiários, expressaram seu consentimento no acordo de solução amistosa. Em todos os casos, a solução amistosa deverá ter por base o respeito aos direitos humanos reconhecidos na Convenção Americana sobre Direitos Humanos, na Declaração Americana e em outros instrumentos aplicáveis.

6. Se não for alcançada uma solução amistosa, a Comissão dará prosseguimento à tramitação da petição ou caso. (COMISIÓN INTERAMERICANA DE DERECHOS HUMANOS, 2009, p. 13)

Entretanto, como se observa, a Convenção Interamericana de Direitos Humanos e o Regulamento da Comissão Interamericana de Direitos Humanos trazem o procedimento de solução amistosa de forma pouco profunda se reservando a sua possibilidade e sua relação ao procedimento ordinário de uma denúncia perante a Comissão Interamericana de Direitos Humanos, não aprofundando a forma como irá ocorrer, no que consiste, estabelecimento de prazos, dentre outros. Nesse sentido:

En nuestra consideración es, en sí mismo, todo un procedimiento que pese a no tener etapas claramente definidas implica el desarrollo de diferentes momentos y acciones por parte de quienes intervienen. No obstante lo anterior, este procedimiento desde su introducción ha carecido de reglas claras y detalladas, funcionando más bien a partir de la experiencia práctica que han ido adquiriendo a través de los años la CIDH, así como los peticionarios y los Estados. (CASTILLA, 2007, p. 126)

A ausência de um procedimento rígido para a solução amistosa gera duas repercussões, a primeira de natureza positiva, pois, a partir da ausência de especificidades do procedimento é possível seu manejo de forma que seja adaptável as necessidades observadas pela Comissão Interamericana de Direitos Humanos e pelas partes, ou seja, não há amarras com relação ao procedimento de solução amistosa. Já a segunda tem natureza negativa, uma vez que a partir do momento que não há regras estabelecidas a respeito do procedimento, pode desencadear seu esvaziamento e provocar sua inutilização no campo prático.

Com relação ao efeito negativo, Jorge Ulises Carmona Tinoco relaciona a questão da baixa utilização do procedimento e a ausência de regras claras e detalhadas que tornou a 
prática do procedimento de solução amistosa baseada na experiência da Comissão Interamericana:

la característica distintiva del procedimiento desde su introducción en la $\mathrm{CADH}$ ha sido su falta de utilización y la carencia de reglas claras y detalladas. De hecho, la forma en que opera el procedimiento está basada por completo en la experiencia práctica adquirida paulatinamente por la $\mathrm{CIDH}$ (2005, p. 103)

Apesar do efeito negativo e a previsão legal ter sido reservada apenas para regras gerais e existência do mecanismo, a Comissão, conforme sua experiência, tem a oportunidade de utilizar o procedimento conforme balizas que melhor se amoldam ao caso, sendo possível adotar táticas que melhor repercutem na formação de um acordo. Nesse caso, ao atuar na promoção de um acordo entre as partes, a Comissão passa a exercer um papel diverso do tradicional:

A comissão, nessa fase, exerce um papel político-diplomático, isto é, atua como uma espécie de árbitro na mediação de um acordo entre as partes envolvidas, abrindo, assim, a possibilidade de solução amistosa, antes de a Comissão vir a emitir relatório com as eventuais recomendações acerca do caso. Assim como no direito brasileiro, as partes não são obrigadas a se submeter ao procedimento conciliatório, pois, trata-se, na espécie, de direito subjetivo (RIO; RIBEIRO, 2014, p. 35)

Além do papel político-diplomático que a Comissão Interamericana exerce ao realizar o procedimento de solução amistosa, também exercerá um papel ativo na construção de uma solução amistosa entre vítima e Estado. Entretanto, muitas vezes esse trabalho na confecção de um acordo pode não render frutos:

Las soluciones amistosas son un medio eficaz para alcanzar la reparación de las víctimas de derechos humanos ajustadas a sus intereses y necesidades, cuando son empleadas, pero presentan un uso limitado y enfrentan ciertos desafios a la hora de ponerse en práctica tales como: la falta de información sobre el mecanismo; la dilación de los procesos durante la negociación; la posible desconfianza entre las partes; y la necesidad de promoción de mayores espacios de diálogo para un seguimiento eficaz al cumplimiento de los acuerdos por parte del Estado (COMISIÓN INTERAMERICANA DE DERECHOS HUMANOS, 2013, p. 1)

Ao perpassar a atuação da Comissão com relação à solução amistosa, por muito tempo não houve um trabalho em torno do procedimento, se privilegiando o procedimento comum de apresentação da petição, requisição de informações, decisão de mérito sobre a violação de direitos humanos e remessa do caso à Corte Interamericana de Direitos Humanos. 
Entretanto, com o decorrer do tempo, observou-se a potencialização dos meios de solução alternativa de conflitos em decorrência de uma crise no direito moderno que provocou o aumento da demanda judicial, da litigiosidade em um modelo de tomada de decisões centralizado e formal e a busca por modos que sejam alternativos as decisões proferidas por órgãos públicos, juízes, baseado em formas alternativas de resolução de conflitos (VALERIO, 2016).

A potencialização dos meios alternativos de solução de conflitos repercutiu diretamente no procedimento de solução amistosa do Sistema Interamericano. Assim, a busca por solução alternativas, não se limitou apenas a ordenamentos jurídicos internos, mas também envolveu o Sistema Interamericano de Direitos Humanos e, a partir disso, a solução amistosa ganha espaço na Comissão Interamericana de Direitos Humanos.

\section{PROCEDIMENTO DE SOLUÇÃo AMISTOSA NO FOCO DO Plano ESTRATÉGICO 2017-2021}

O acesso ao Sistema Interamericano de Direitos Humanos ocorre através do Sistema de Petições da Comissão Interamericana de Direitos Humanos, ou seja, o julgamento de um caso perante a Corte depende antes do recebimento da denúncia/petição e da resolução de mérito por parte da Comissão.

Nesse caso, ao longo do tempo houve um aumento do número de petições enviadas para apreciação pela Comissão Interamericana de Direitos Humanos. De acordo com o Informe Anual da Comissão Interamericana de Direitos Humanos de 2006, em 1997 foram apresentadas 435 petições, por sua vez, em 2006 foram apresentadas 1325 petições, um aumento de 304\% (COMISIÓN INTERAMERICANA DE DERECHOS HUMANOS, 2006). Por sua vez, em 2019 foram apresentadas 2.534 petições perante a Comissão, (COMISIÓN INTERAMERICANA DE DERECHOS HUMANOS, 2020) um aumento de $191 \%$ com relação a 2006 e 582\% com relação a 1997. De acordo com a Comissão, 1237 petições apresentadas terminaram o ano de 2006 sem que fossem analisadas (COMISIÓN INTERAMERICANA DE DERECHOS HUMANOS, 2006).

O acúmulo de trabalho da Comissão Interamericana e o aumento do número de petições apresentadas gerou o atraso processual nos trabalhos desenvolvidos pela Comissão e, 
consequentemente, a diminuição de uma prestação jurisdicional efetiva para as vítimas de violações de direitos humanos.

Com ciência a respeito de tais fatos, a Comissão Interamericana elegeu em seu Plano Estratégico 2017-2021 a redução da morosidade processual como um dos aspectos centrais no desenvolvimento de seus trabalhos:

La CIDH adoptará decisiones para poner en práctica las medidas necesarias para responder oportuna y eficazmente a las víctimas y a los Estados. Entre las medidas especiales para la reducción del atraso procesal que se han puesto en marcha y las nuevas medidas que se implementarán de forma más decisiva se destacan: la aplicación estricta de requisitos de apertura a trámite, la política de archivo y desactivación definitiva de peticiones, la sistematización de criterios de agotamiento y plazo de presentación, la especialización por portafolios en todas etapas procesales, la creación de formatos de informe de fondo aplicables a temas recurrentes, la revisión de portafolio de casos con los Estados y la construcción de estrategias de país. Será también creada una unidad de gestión a cargo de: apoyo administrativo requerido; elaboración y actualización de protocolos, instructivos y guías; mapeo de flujos y procedimientos; creación de nuevas herramientas y generación de estadísticas y reportes actualizados mediante las cuales mejorará las posibilidades de recoger y producir información relevante para las personas usuarias del sistema. (COMISIÓN INTERAMERICANA DE DERECHOS HUMANOS 2017, p. 51)

A Comissão Interamericana buscou formas de resolução do atraso processual e, nesse caso, o procedimento de solução amistosa atua junto com os esforços de redução da morosidade processual pois seria possível não apenas a diminuição do tempo do trâmite dentro da Comissão como também evitar o envio do caso à Corte Interamericana abreviando a permanência do caso no Sistema Interamericano de Direitos Humanos. Dessa forma, o procedimento significa a redução da morosidade processual pelo aspecto de acúmulo de trabalho e pelo tempo ordinário que um caso iria percorrer na Comissão e posteriormente, se for o caso, na Corte.

Nesse contexto, a Comissão elege o procedimento de solução amistosa como uma forma de redução de morosidade processual e decide adotar mecanismos que permitam ampliar sua utilização:

Adicionalmente, la CIDH ha decidido profundizar sus esfuerzos para expandir el uso del mecanismo de soluciones amistosas y ampliar el acceso a éste, mediante cambios de procedimiento y metodología que permitan informar e impulsar proactivamente el uso de este mecanismo, con la 
voluntad expresa de las partes (COMISIÓN INTERAMERICANA DE DERECHOS HUMANOS, 2017, p. 51)

A partir do Plano Estratégico 2017-2021, é possível observar um novo cenário para o procedimento de solução amistosa no Sistema Interamericano de Direitos Humanos, de um espaço de menor visibilidade para um com maior ênfase na resolução de demandas sobre violações de direitos humanos. Para a concretização das soluções amistosas se entendeu a necessidade da adoção de metodologias e técnicas, de forma a trazer robustez ao espaço de negociação entre vítima e Estado.

El programa se centrará en la aplicación de un protocolo y metodología de soluciones amistosas actualizados, en la elaboración de herramientas que faciliten a las personas usuarias del sistema de peticiones y casos acceder a información sobre el procedimiento de soluciones amistosas, en ampliar la asesoría técnica a las partes y en dar a conocer ejemplos actualizados de resultados alcanzados a favor de las víctimas de violaciones de derechos humanos, sus familiares y la sociedad. Promoverá el intercambio y difusión de buenas prácticas en soluciones amistosas y la capacitación sobre el uso del mecanismo. Asimismo, pretende avanzar en el establecimiento de nuevas prácticas y métodos de resolución de conflictos dirigidos a impulsar tanto procedimientos y negociaciones, como el cumplimiento de los acuerdos en ejercicio de su rol de facilitadora de los procesos de soluciones amistosas (COMISIÓN INTERAMERICANA DE DERECHOS HUMANOS, 2013, p. 52)

Assim, o espaço por muito tempo não concedido ao procedimento de solução amistosa, justificado pela dificuldade na estruturação do procedimento, métodos, além da possível desconfiança das partes para a participação e a limitações ao seu uso, passa a ser ocupado de forma a trazer protagonismo ao procedimento por meio da previsão de procedimentos e normas que tornam o que antes era apenas um mecanismo previsto mas sem prática em uma forma de solução de conflitos e espaço de conciliação entre vítima e Estado.

Dessa forma, o balanço de implementação do plano estratégico 2017-2021 demonstra o trabalho da Comissão Interamericana em estruturar a solução amistosa de modo a garantir sua aplicação de forma efetiva:

La Comisión consideró necesario adoptar lineamientos básicos para dar un carácter semi-estructurado a los procesos de negociación, preservando la flexibilidad del procedimiento, y al mismo tiempo, atendiendo a los principios de celeridad y voluntariedad que deben regir los mecanismos alternativos de resolución de conflictos (COMISIÓN INTERAMERICANA DE DERECHOS HUMANOS, 2020, p. 13) 
A decisão de estabelecer procedimentos e normas a respeito da solução amistosa contribuiu para os avanços dos trabalhos de alcançar uma solução no caso de violações dos Direitos Humanos:

En los primeros 6 meses de 2020, la Comisión ha facilitado 10 reuniones de trabajo en diferentes asuntos bajo negociación y seguimiento de implementación de acuerdos de solución amistosa (ASAs), tanto de manera presencial como virtual, a partir de la adopción de nuevas metodologías para el impulso de la suscripción y cumplimiento de acuerdos. En el mismo sentido, se han sostenido 52 reuniones técnicas de impulso de procesos de solución amistosa de carácter bilateral y tripartito con la presencia de peticionarios, Estados, Comisionados y facilitadoras de la Sección de Soluciones Amistosas (SSAS), con la aplicación de métodos de resolución alternativa de conflictos (COMISIÓN INTERAMERICANA DE DERECHOS HUMANOS, 2020, p. 14)

Entretanto, apesar da solução amistosa ter ganho outra perspectiva a respeito de sua relevância, ainda persiste o paradigma de sua utilização. Considerando que não se trata do procedimento comum de uma denúncia/petição na Comissão Interamericana e envio do caso à Corte, deve-se realizar a análise a respeito do procedimento de solução amistosa como um mecanismo de oferecimento obrigatório para as vítimas e Estados ou apenas como uma forma de resolução de conflitos alternativa a ser oferecida a partir da discricionariedade da Comissão Interamericana de Direitos Humanos.

\section{O OFERECIMENTO DO PROCEDIMENTO DE SOLUÇÃO AMISTOSA COMO ATO VINCULADO DA COMISSÃO INTERAMERICANA DE DIREITOS HUMANOS}

O procedimento de solução amistosa ganhou relevância no Sistema Interamericano de Direitos Humanos a partir do Plano Estratégico 2017-2021 da Comissão Interamericana, sendo que o procedimento passou a ser estruturado em trono de técnicas, incentivos a sua realização, estratégias e o estabelecimento de prazos, porém, o procedimento é meio alternativo de solução de conflitos no âmbito interamericano de direitos humanos e, dessa forma, por não se tratar do procedimento comum, nasce a discussão se a tentativa de solução amistosa é uma obrigatoriedade ou uma possibilidade.

O artigo 40 do Regulamento da Comissão Interamericana de Direitos Humanos preceitua que a Comissão, a qualquer tempo durante o exame da denúncia, se colocará à 
disposição das partes para uma solução amistosa sobre o assunto, podendo inclusive isso acontecer por iniciativa das partes.

Ao se analisar o artigo, em tese não se percebe a obrigação por parte da Comissão em promover a solução amistosa entre denunciante e Estado, mas sim apenas que se colocará à disposição das partes quando desejarem chegar a uma solução amistosa.

A respeito do oferecimento do procedimento, a Corte Interamericana se pronunciou e alterou seu entendimento ao longo do tempo. A Sentença de Exceções Preliminares do caso Velásquez Rodríguez Vs. Honduras de 26 de junho de 1987 trata do procedimento de solução amistosa como uma faculdade:

Desde un punto de vista literal, la frase utilizada por el artículo 48.1.f) de la Convención, la Comisión "se pondrá a disposición de las partes interesadas, a fin de llegar a una solución amistosa", parece establecer un trámite obligatorio. Sin embargo, la Corte considera que una interpretación, de acuerdo con el contexto de la Convención, lleva al convencimiento de que esa actuación de la Comisión debe intentarse sólo cuando las circunstancias de una controversia determinen la necesidad o la conveniencia de utilizar este instrumento, supuestos sujetos a la apreciación de la Comisión. (CORTE INTERAMERICANA DE DERECHOS HUMANOS, 1987, p. 9)

O entendimento se manteve no Caso Fairén Garbi y Solís Corrales vs Honduras (1987) e Caso Godínez Cruz (1987) (CORTE INTERAMERICANA DE DERECHOS HUMANOS, 1994). Entretanto, na Sentença de Exceções Preliminares de 21 de janeiro de 1994 sobre o Caso Caballero Delgado y Santana vs. Colômbia, a Corte assim decidiu:

Es muy clara la intención de la Convención respecto del papel conciliador que debe cumplir la Comisión antes de que un caso sea enviado a la Corte o publicado.

Sólo en casos excepcionales y, naturalmente, con razones de fondo, puede la Comisión omitir el procedimiento de la conciliación porque está de por medio la protección de los derechos de las víctimas o de sus familiares. No parece ser suficiente decir, como lo hace la Comisión, que no se acudió a este procedimiento simplemente por razón de la "naturaleza" del asunto.

28. La Corte estima que la Comisión debió fundamentar cuidadosamente su rechazo a la solución amistosa, de acuerdo con la conducta observada por el Estado a quien se imputa la violación. (CORTE INTERAMERICANA DE DERECHOS HUMANOS, 1994, p. 7)

Dessa forma, a partir do Caso Caballero Delgado y Santana vs. Colômbia, o primeiro do Estado colombiano na Corte Interamericana, nota-se uma mudança de entendimento a respeito do procedimento de solução amistosa ser facultativo ou vinculado 
pela Comissão Interamericana de Direitos Humanos, decidindo a Corte que seu oferecimento é obrigatório.

Com relação à doutrina, não é pacífico o entendimento sobre a obrigatoriedade ou não do procedimento de solução amistosa. Para Castilla, o entendimento da Corte Interamericana inicialmente era de que se tratava de um ato discricionário da Comissão, mas posteriormente o entendimento passou a ser de que se trata de uma obrigatoriedade (2007).

Por seu turno, Estepa entende que o procedimento anteriormente é uma faculdade da Comissão Interamericana de Direitos Humanos, firmando seu entendimento no Caso Caballero Delgado y Santana vs. Colômbia:

la Corte Interamericana ha señalado que este arreglo amistoso "debe intentarse sólo cuando las circunstancias de una controversia determinen la necesidad o la conveniencia de utilizar este instrumento, supuestos sujetos a la apreciación de la Comisión"; en el primer caso colombiano que llegó a su conocimiento, también se pronunció en la misma dirección (Caso Caballero Delgado y Santana vs. Colombia, sentencia del 21 de enero de 1994, Excepciones preliminares, serie C No 17, párr. 26). (ESTEPA, 2011, p. 333)

Entretanto, as bases do argumento estão incorretas. Afirma a autora que no caso Caballero Delgado y Santana v. Colômbia a Corte entendeu pelo procedimento de solução amistosa como uma faculdade, em igualdade com o decidido no caso Valásquez Rodrigues vs. Honduras, Fairén Garbi y Sólis Corrales vs. Honduras e Godínez Cruz vs. Honduras, entretanto, conforme transcrito acima, no caso Caballero Delgado y Santana vs. Colômbia houve uma mudança de entendimento, sendo este o mantido até a atualidade.

No mesmo caso (Caballero Delgado y Santana vs. Colômbia) a Corte também entendeu que nos casos em que a Comissão decida por não oferecer o procedimento de solução amistosa, isso deve acontecer de forma fundamentada, ou seja, a Comissão só pode decidir pela desnecessidade do procedimento de solução amistosa por meio de decisão fundamentada que conste as razões pelas quais não fora oferecido a possibilidade de solução amistosa.

Após a Sentença de Exceções Preliminares do caso Caballero Delgado y Santana vs. Colômbia, a Comissão Interamericana alterou sua prática e passou a oferecer o procedimento de solução amistosa para as partes: 
Con este criterio, se recuperó de cierta forma la obligación que tiene la Comisión de invitar a las partes a iniciar un procedimiento de este tipo y cuando niegue esta posibilidad deberá hacerlo fundadamente. Esto ocasionó que prácticamente después de esas decisiones, la CIDH cambiara su práctica y actualmente en la gran mayoría de peticiones al momento de ser admitidas como casos, la Comisión hace el ofrecimiento previsto en el artículo 48.1.f. de la CADH. Lo anterior no significa que la CIDH pueda imponer u obligar a las partes a iniciar el procedimiento de solución amistosa; sólo puede invitar,13 y son las partes (peticionarias/os - Estado) las únicas que tienen en sus manos la decisión de aceptar y/o solicitar el inicio de una solución amistosa. (CASTILLA, 2007, p. 127)

Em seguida a decisão da Corte Interamericana de Direitos Humanos, a solução amistosa deixa de ser um mecanismo apenas previsto e passa a ser ofertado para às partes do procedimento como uma forma alternativa de resolução de conflitos acerca de direitos humanos.

Porém, apenas a partir do Plano Estratégico 2017-2021 da Comissão que a solução amistosa é vista como protagonista na chegada a solução de litígios no Sistema Interamericano de Direitos Humanos. Mecanismos, como a Resolucion 03/2020 que trata e ações diferenciadas para redução do atraso processual no procedimento de solução amistosa, são instituídos com vistas a promover a solução amistosa (COMISÍON INTERAMERICANA DE DERECHOS HUMANOS, 2020)

Dessa forma, antes a solução amistosa era mera faculdade por parte da Comissão Interamericana de Direitos Humanos mas, após decisão do Caso Caballera Delgado y Santana vs. Colômbia, passa a ser obrigatória. Entretanto, para além disso, deve-se observar que atualmente, através do Plano Estratégico 2017-2021 da Comissão Interamericana de Direitos Humanos, a solução amistosa passa a ser estruturada e prevista não como um mecanismo alternativo, mas como parte do trâmite da denúncia na Comissão.

Apesar a decisão da Corte sobre a necessidade de oferecimento do procedimento de solução amistosa, resta a discussão se isso se aplica aos casos de todas as naturezas tramitando na Comissão ou se há um limite como sobre os casos que dizem respeito a violações do direito à vida, tortura e outros. De acordo com Bruno inicialmente havia um limite para a aplicação do procedimento de solução amistosa:

A princípio, a CIDH adotou o posicionamento de que conflitos referentes aos direitos à vida, à integridade pessoa e à liberdade pessoal não eram passíveis de solução amistosa pela natureza grave das transgressões. Nesses 
casos, a CIDH dava seguimento à tramitação da petição, sem consultar as partes sobre a possibilidade de se tentar solução não contenciosa para o conflito. O único acordo dessa natureza aprovado, entre 1985 e 199519, não foi proposto pela CIDH, mas pelos familiares e pelos representantes das vítimas dos Casos 10.288, 10.310, 10.436, 10.49610 .631 e 10.771 e aceito pelo Governo argentino em 1993 (BRUNO, 2017, p. 14)

Apesar do entendimento inicial que, quando a denúncia versar sobre violação do direito à vida, à integridade pessoal e à liberdade pessoal, não poderiam ser submetidos a solução amistosa em razão da gravidade da transgressão, o Guia Prático sobre Soluções Amistosas elaborado pela Comissão prevê:

Todos los Estados miembros de la Organización de Estados Americanos, pueden hacer uso del mecanismo de solución amistosa aunque no hayan ratificado aun la Convención Americana sobre Derechos Humanos, a la luz de la Declaración Americana de los Derechos y Deberes del Hombre. Asimismo, independientemente de la naturaleza del asunto, la CIDH ofrece sus buenos oficios, en todos los casos, para facilitar que las partes lleguen a un acuerdo respetuoso de los derechos humanos. (COMISIÓN INTERAMERICANA DE DERECHOS HUMANOS, 2013, p. 5)

Não há, portanto, no entendimento da Comissão nenhum caso que não seja passível de ser submetido ao procedimento de solução amistosa, independente da natureza e sobre a violação de qual direito possa versar, sendo o requisito essencial a concordância das partes na negociação e no acordo celebrado.

Ademais, no quadro de aumento da solução amistosa relevante ressaltar a conclusão de Flávia Piovesan a respeito das interações entre diferentes atores no Sistema Interamericano de Direitos Humanos

O sistema interamericano é capaz de revelar as peculiariedades e especificidades das lutas emancipatórias por direitos e por justiça na região latino-americana. O sistema apresenta uma particular institucionalidade marcada pelo protagonismo de diversos atores, em um palco em que interagem Estados, vítimas, organizações da sociedade civil nacionais e internacionais, a Comissão e a Corte Interamericana no âmbito da Organização dos Estados Americanos (2014, p. 89)

Posto isso, a obrigatoriedade do oferecimento do procedimento de solução amistosa se perfaz a partir da decisão da Corte Interamericana de Direitos Humanos no caso Caballera Delgado y Santana vs. Colômbia em 1994, que estabeleceu que a Comissão não tem a discricionariedade para oferecer o procedimento a não ser por meio de ser decisão fundamentada. Além disso, a obrigatoriedade de oferecimento do procedimento se reforça a partir do foco trazido pelo Plano Estratégico 2017-2021, quando há a mudança do 
procedimento de solução amistosa como apenas meio alternativo para forma de resolução parte procedimento da Comissão no Sistema Interamericano de Direitos Humanos.

\section{CONCLUSÃO}

O procedimento de solução amistosa é mecanismo da Comissão Interamericana de Direitos Humanos para a resolução de conflitos de modo alternativo ao procedimento comum de trâmite do caso, decisão de mérito, recomendações e possível envio à Corte.

Entretanto, inicialmente o procedimento de solução amistosa, por ser apenas previsto como uma possibilidade e carecer de instrumentos e estratégias, não tinha utilização relevante e era visto apenas como uma alternativa onde vítimas e Estado chegariam a um acordo a respeito de violações de direitos humanos.

A partir do Plano Estratégico 2017-2021 da Comissão Interamericana de Direitos Humanos e em razão do acúmulo de denúncias para tramitarem perante a Comissão, a solução amistosa passa a ser foco como forma de resolução de conflitos, sendo estruturado por meio de técnicas de negociação, prazos e estudos que garantam a efetividade do procedimento.

Nesse cenário, surge a problemática acerca do procedimento de solução amistosa ter caráter vinculado ou discricionário com relação ao seu oferecimento pela Comissão Interamericana para as partes.

A Corte na Sentença de Exceções Preliminares do caso Caballero Delgado y Santana vs. Colômbia em 21 de janeiro de 1994 decidiu que a Comissão deve oferecer o procedimento de solução amistosa para as partes, sendo que quando decidir não fazer isso deve ser em bases fundamentadas.

Após a decisão no caso Caballero Delgado y Santana vs. Colômbia, a Comissão passou a oferecer o procedimento nos casos em trâmite e a partir do referido Plano Estratégico 2017-2021 o procedimento ganhou também estrutura e técnicas.

Dessa forma, é possível concluir que atualmente o procedimento de solução amistosa tem o seu oferecimento obrigatório pela Comissão Interamericana de Direitos Humanos. Tal fato decorre da decisão da Corte no caso Caballero Delgado y Santana vs. Colômbia e, além disso, da relevância em razão de ter sido eleita como forma de redução da morosidade processual e de resolução de conflitos no Sistema Interamericano de Direitos Humanos, 
deixando de ser apenas um instrumento alternativo para compor o trâmite ordinário das denúncias na Comissão Interamericana.

\section{REFERÊNCIAS}

BRUNO, Maíra Bogo. Solução Amistosa de Conflitos Individuais Perante a Comissão Interamericana de Direitos Humanos como Alternativa ao Procedimento Contencioso. 2017. Dissertação (Mestrado em Direito) - Centro Universitário de Brasília, Brasília. 2017. Disponível em: https://repositorio.uniceub.br/jspui/bitstream/prefix/12784/1/61500110.pdf. Acesso em: 02 set. 2021

CARMONA TINOCO, Jorge Ulises. La solución amistosa de peticiones de derechos humanos en el ámbito universal y regional, con especial referencia al sistema interamericano. Anuario Mexicano de Derecho Internacional, [S.1.], jan. 2005. ISSN 2448-7872. Disponible en: <https://revistas.juridicas.unam.mx/index.php/derechointernacional/article/view/116>. Fecha de acceso: 01 set. 2021. DOI: http://dx.doi.org/10.22201/iij.24487872e.2005.5.116.

CASTILLA, Karlos. Ideas respecto a la solución amistosa en el Sistema Interamericano de Derechos Humanos. Revista CEJIL, San José, ano 2, n. 3, p. 124-133, set. 2007. Disponível em: http://www.corteidh.or.cr/tablas/r24786.pdf. Acesso em: 15 set. 2021

COMISIÓN INTERAMERICANA DE DERECHOS HUMANOS. Acciones diferenciadas para atender el atraso procesal en procedimientos de Solución Amistosa. Resolución 3/2020, 21 de abril de 2020. Disponível em: http://bit.ly/resolucao3-2020. Acesso em 18 set. 2021

COMISIÓN INTERAMERICANA DE DERECHOS HUMANOS. Informe Anual 2020. Washington: Organización de los Estados Americanos, 2020. p. 74-305. Disponível em: https://www.oas.org/es/cidh/docs/anual/2020/FB/Default.html\#p=311. Acesso em: 12 set. 2021.

COMÍSION INTERAMERICANA DE DERECHOS HUMANOS. Informe Anual de La Comisíon Interamericana de Derechos Humanos: capítulo III - el sistema de peticiones y casos individuales. Capítulo III - El sistema de Peticiones y Casos Individuales. 2006.

Disponível em: http://www.cidh.oas.org/annualrep/2006sp/cap3.2006.sp.htm. Acesso em: 10 set. 2021.

COMISIÓN INTERAMERICANA DE DERECHOS HUMANOS. Plan Estratégico 20172021. 2017. Disponível em: https://bit.ly/2XdM4tA. Acesso em: 08 set. 2021.

COMISIÓN INTERAMERICANA DE DERECHOS HUMANOS. Informe de Balance de Implementación del Plan Estratégico CIDH 2017-2021. Washington: Comisión Interamericana de Derechos Humanos, 2020. 86 p. Disponível em: http://www.oas.org/es/cidh/prensa/comunicados/2020/BIPESemestral2020.pdf. Acesso em: 09 set. 2021.

COMISSÃO INTERAMERICANA DE DIREITOS HUMANOS. Guia práctica sobre el uso del mecanismo de soluciones amistosas en el sistema de peticiones y casos ante la CIDH. Washington, D.C: CIDH, 2013. Disponível em: 
https://www.oas.org/es/cidh/soluciones_amistosas/docs/guia-practica-sa-es.pdf. Acesso em: 10 set. 2021

\section{COMISSÃO INTERAMERICANA DE DIREITOS HUMANOS. Regulamento da}

Comissão Interamericana de Direitos Humanos. Aprovado pela Comissão em seu $137^{\circ}$ período ordinário de sessões, realizado de 28 de outubro a 13 de novembro de 2009. Washington D.C: CIDH, 2009. Disponível em: http://www.cidh.org/Basicos/Portugues/u.Regulamento.CIDH.htm. Acesso em: 10 set. 2021

CORTE INTERAMERICANA DE DERECHOS HUMANOS. Caso Caballero Delgado y Santana vs. Colombia, 8 de diciembre de 1995. Disponível em: https://www.corteidh.or.cr/docs/casos/articulos/seriec_17_esp.pdf. Acesso em: 2 set. 2021

CORTE INTERAMERICANA DE DERECHOS HUMANOS. Caso Velásquez Rodríguez Vs. Honduras, 26 de junho de 1987. Disponível em: http://www.corteidh.or.cr/docs/casos/articulos/seriec_22_esp.pdf. Acesso em: 2 set. 2021

ESTEPA, María Carolina. La solución amistosa en el marco del Sistema Interamericano de Derechos Humanos. Revista de Estudios Socio-jurídicos, Bogotá, v. 13, n. 2, p. 327-352, jul./dic. 2011. Disponível em: https://www.redalyc.org/pdf/733/73322590012.pdf. Acesso em: 10 set. 2021

ORGANIZAÇÃO DE ESTADOS AMERICANOS. Convenção Americana sobre Direitos Humanos, de 22 de novembro de 1969. San José: OEA, 1969. Disponível em: https://www.cidh.oas.org/basicos/portugues/c.convencao_americana.htm. Acesso em: 28 ago. 2021.

RIO, José Justino do; RIBEIRO, Maria Perini Antunes. O Acesso à Justiça e o Papel da Comissão Interamericana de Direitos Humanos. Revista Em Tempo, Marília, v. 13, n. 1, p. 01-51, 2014

VALÉRIO, Marco Aurélio Gumieri. Os meios alternativos de resolução de conflitos e a busca pela pacificação social. Revista de Direito Privado, [s. 1], v. 69, n. 1, p. 1-10, 15 dez. 2016. Disponível em: https://bit.ly/3nq7ChE. Acesso em 10 set. 2021

PIOVESAN, Flávia. Sistema Interamericano de Direitos Humanos: impacto transformador, diálogos, jurisdicionais e os desafios da reforma. Revista Direitos Emergentes na Sociedade Global, Santa Maria, v. 3, n. 1, p. 76-101, 16 dez. 2014. Disponível em: https://periodicos.ufsm.br/REDESG/article/view/16282/pdf\#.YUjK9eySnDe. Acesso em: 10 set. 2021 